Dario Balesdent Filho

\title{
Estratégias Competitivas Pós-Privatização Para As Empresas Concessionárias de Serviço Telefônico Fixo Comutado (STFC) no Brasil: Um Estudo de Caso
}

Dissertação de Mestrado (Opção profissional) Dissertação apresentada como requisito parcial para obtenção do título de Mestre pelo Programa de PósGraduação em Administração da PUC-Rio.

Orientador: Prof. Jorge Ferreira da Silva 
Dario Balesdent Filho

\author{
Estratégias Competitivas Pós-Privatização Para As \\ Empresas Concessionárias de Serviço Telefônico Fixo \\ Comutado (STFC) no Brasil: Um Estudo de Caso
}

Dissertação apresentada como requisito parcial para obtenção do título de Mestre pelo Programa de Pós-Graduação em Administração da PUC-Rio. Aprovada pela Comissão Examinadora abaixo assinada.

\author{
Prof. Jorge Ferreira da Silva \\ Orientador \\ Departamento de Administração, PUC-Rio \\ Prof ${ }^{\mathrm{a}}$. Hélène Bertrand \\ Departamento de Administração, PUC-Rio \\ Prof $^{a}$. Ângela Maria Cavalcanti da Rocha \\ COPPEAD, UFRJ \\ Prof. João Pontes Nogueira
} Vice-Decano de Pós-Graduação do Centro de Ciências Sociais - PUC-Rio 
Todos os direitos reservados. É proibida a reprodução total ou parcial do trabalho sem autorização da universidade, do autor e do orientador.

\section{Dario Balesdent Filho}

Graduou-se em Economia na Faculdade Cândido Mendes em 1993. Trabalhou em diversas instituições do mercado financeiro entre 1987 e 1994. Posteriormente, entre 1994 e 2000, trabalhou na Souza Cruz S.A., ocupando cargos de gerência na área de finanças. Desde 2000 trabalha na Embratel S.A., estando atualmente responsável pela área de Alianças Estratégicas.

Ficha Catalográfica

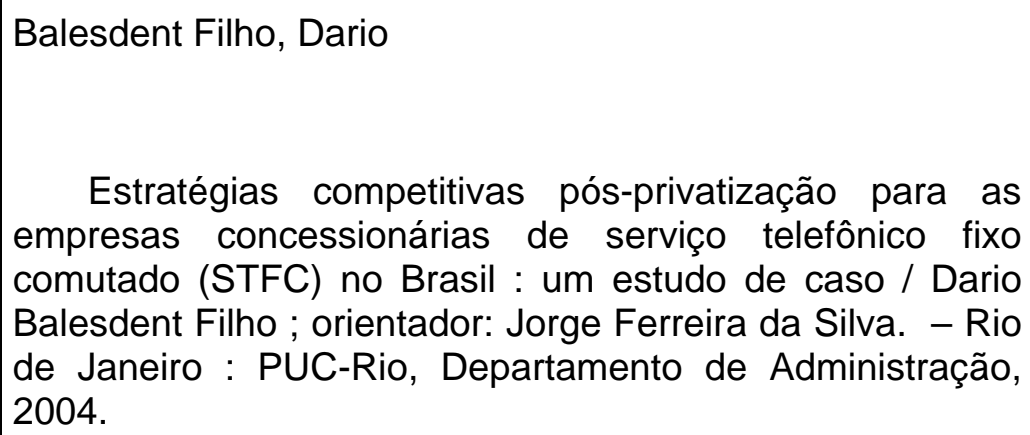

Estratégias competitivas pós-privatização para as empresas concessionárias de serviço telefônico fixo comutado (STFC) no Brasil : um estudo de caso / Dario Balesdent Filho ; orientador: Jorge Ferreira da Silva. - Rio de Janeiro : PUC-Rio, Departamento de Administração, 2004.

138 f. : il. : $30 \mathrm{~cm}$

Dissertação (mestrado) - Pontifícia Universidade Católica do Rio de Janeiro, Departamento de Administração.

Inclui referências bibliográficas.

1. Administração - Teses. 2. Posicionamento estratégico. 3. Sistemas telefônicos - Administração. 4. Concorrência. 5. Mudanças do ambiente competitivo. I. Silva, Jorge Ferreira da. II. Pontifícia Universidade Católica do Rio de Janeiro. Departamento de Administração. III. Título. 


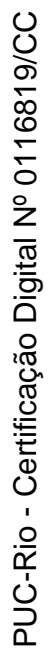

Para minha esposa, Anna Paula, pelo apoio, dedicação, confiança e carinho. 


\section{Agradecimentos}

Ao meu orientador Professor Jorge Ferreira da Silva pelos ensinamentos, estímulo, apoio, e, principalmente, pela paciência em compartilhar seu conhecimento.

Aos meus pais, Dario e Maria Inês, e padrasto, Suly Liberman, pela educação e oportunidades oferecidas.

Aos meus colegas de mestrado da PUC-Rio pelo intercâmbio de conhecimento e experiências, que contribuíram para a conclusão deste trabalho.

Ao meu chefe e colega de trabalho, Nelson Laureano, pelo incentivo e apoio, principalmente no início do curso.

À minha esposa, Anna Paula, pela compreensão acerca dos momentos de ausência, principalmente durante a gravidez e nascimento de nosso filho. 


\section{Resumo}

Balesdent Filho, Dario. Estratégias competitivas pós-privatização para as empresas concessionárias de serviço telefônico fixo comutado (STFC) no Brasil : um estudo de caso. Rio de Janeiro, 2004. 138 p. Dissertação de Mestrado -Departamento de Administração, Pontifícia Universidade Católica do Rio de Janeiro.

A indústria de telecomunicações no Brasil vem passando por profundas transformações desde meados da década de 1990, quando da alteração da regulamentação e da privatização do monopólio estatal prestador de serviço telefônico fixo comutado (STFC). No arcabouço regulatório da indústria, estas alterações implicaram em grandes transformações no ambiente competitivo e nas estratégias competitivas adotadas pelas empresas concessionárias originárias a partir deste momento. A partir do estudo de caso de uma empresa concessionária privatizada em 1998, procurou-se identificar alterações em suas estratégias competitivas, em seu ambiente competitivo e no desempenho desta empresa, antes e após a privatização. A identificação das estratégias competitivas foi baseada na classificação da empresa, a partir de 20 variáveis estratégicas, segundo a tipologia de Porter (1986), em entrevistas com funcionários e ex-funcionários da empresa selecionada, concorrentes e consultorias especializadas no setor. No período anterior à privatização (19961998), dado o regime de monopólio estatal no qual a empresa selecionada operava, não foi possível identificar um posicionamento estratégico bem definido, apesar da proximidade com a estratégia de diferenciação. Já no período posterior à privatização (1999-2003), a empresa busca um posicionamento estratégico de diferenciação, apesar de algumas ações táticas inconsistentes com esta estratégia. A comparação dos indicadores de desempenho apurados antes e após a privatização indica que, apesar da empresa adotar com sucesso um posicionamento de diferenciação, a significativa transformação do ambiente competitivo foi desfavorável, tornando o ambiente competitivo mais hostil e prejudicando os resultados da empresa. 


\section{Palavras-chave}

Nova regulamentação; mudanças do ambiente competitivo; posicionamento estratégico. 


\section{Abstract}

Balesdent Filho, Dario. Post-privatization competitive strategies for fixed telephony switched services (STFC) concessionaire companies in Brazil : a case study. Rio de Janeiro, 2004. 138 p. MSc. Dissertation Departamento de Administração, Pontifícia Universidade Católica do Rio de Janeiro.

The telecommunications industry in Brazil had been through significant changes during the mid-1990's and the beginning of the $21^{\text {st }}$ century, due to a new regulation and the privatization of the state-owned telephony monopolistic operators. These regulatory changes caused a major transformation in this industry's competitive environment and in the recently privatized operators competitive strategies. This dissertation seeks to identify changes in the competitive environment by means of a more detailed analysis of a privatized operator, this company's competitive strategies and performance indicators through a comparison of two distinct periods - before (1996-1998) and after (1999-2003) the privatization. In order to identify the competitive strategies, the selected company was classified under 20 strategic variables, according to Porter's (1980) typology. The research is based on interviews with current and former employees from the selected company, its competitors and the industry's consulting firms. During the period that preceded the privatization process (19961998), the company's strategy can not be classified under Porter's (1980) typology due to the monopolistic regime in which the company provided its services, although it was possible to infer that the company's strategy seems closer to a differentiation strategy than other generic strategies. On the other hand, during the period following the privatization (1999-2003), the company positioned itself on a differentiation strategy, although some adopted tactics might diverge from this positioning. In spite of successfully adopting a differentiation strategy, the company's results have decreased, as shown by a comparison of performance indicators from both periods. These poorer results after the new regulation are mainly due to a much more hostile competitive environment than before. 


\section{Keywords}

New regulation; competitive environment changes; strategic positioning.

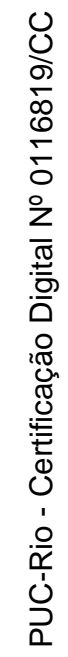




\section{Sumário}

1. PROBLEMA E OBJETIVO 13

1.1. Introdução 13

1.2. Objetivo da Pesquisa 18

1.3. Delimitações do Estudo 19

1.4. Relevância do Estudo 19

2. REFERENCIAL TEÓRICO 21

2.1. Introdução 21

2.2. Ambiente Competitivo 25

2.2.1. Modelo Competitivo na Indústria de STFC no Brasil 26

2.2.1.1. Histórico da Indústria no Brasil 26

2.2.1.2. A Agência Nacional de Telecomunicações 35

2.2.1.3. As Condições para Prestação de Serviços na Modalidade STFC 36

2.2.1.4. Redes Telefônicas e a Interconexão 38

2.2.2. Estrutura da Indústria 42

2.2.2.1. Ameaça de Entrada 45

2.2.2.2. Rivalidade Entre os Concorrentes 51

2.2.2.3. Ameaça de Substitutos 56

2.2.2.4. Poder de Negociação de Fornecedores 57

2.2.2.5. Poder de Negociação de Compradores 58

2.2.3. Atuação do Governo na Indústria 60

2.2.3.1. Influência nas Barreiras de Entrada 61

2.2.3.2. Influência na Rivalidade da Indústria 62

2.2.3.3. Influência sobre a Ameaça de Substitutos 63

2.2.3.4. Influência no Poder de Fornecedores e Compradores 64

2.2.3.5. Papel das Empresas Estatais 65

2.3. Estratégias Competitivas 65

2.3.1. Tipologia de Estratégias Genéricas de Porter (1980) 66

2.3.1.1. Liderança em Custos $\quad 67$

2.3.1.2. Diferenciação 70

$\begin{array}{ll}\text { 2.3.1.3. Enfoque } & 72\end{array}$ 
2.3.1.4. Meio-Termo 73

2.3.2. Críticas à Tipologia de Estratégias Genéricas de Porter (1980) 75

2.4. Conceito de Estratégia Competitiva $\quad 78$

2.5. Desempenho 83

3. METODOLOGIA 86

3.1. Metodologia de Estudo de Caso 86

3.2. Seleção de Empresas e Sujeitos $\quad 89$

3.3. Coleta e Tratamento dos Dados 90

3.4. Operacionalização e Mensuração dos Conceitos 93

3.4.1. Caracterização do Ambiente Competitivo 93

3.4.2. Identificação das Estratégias 94

3.4.3. Seleção de Critérios para Análise de Desempenho 98

3.5. Limitações do Método 99

4. ANÁLISE DE DADOS 103

4.1. Índice de Respostas e Qualificação dos Respondentes 103

4.2. Ambiente Competitivo 103

4.3. Estratégias Competitivas 107

4.4. Análise de Relacionamento entre Estratégia Competitiva, Ambiente $\begin{array}{ll}\text { Competitivo e Desempenho da Empresa } & 109\end{array}$

4.5. Aplicabilidade do Modelo de Estratégias Genéricas de Porter 114

$\begin{array}{ll}5 \cdot \text {. CONCLUSÃO } & 116\end{array}$

6. BIBLIOGRAFIA 120

$\begin{array}{ll}\text { 7. ANEXO } & 128\end{array}$ 


\section{Lista de figuras}

Figura 2.1 - Modelo Estrutura-Ambiente-Desempenho 23

Figura 2.2 - Environmental Analysis Framework de Austin 26

Figura 2.3 - Interconexão entre Redes de Operadoras Locais e Operadoras de

LD 41

Figura 2.4 - As Cinco Forças Competitivas de Porter 44

Figura 2.5 - Barreiras e Rentabilidade $\quad 56$

Figura 2.6 - As Estratégias Genéricas segundo Porter 73

Figura 3.1 - Fórmula de ROA segundo Damodaran 99

Figura 4.1 - Potencial de Desempenho Antes e Após a Nova Regulamentação

\section{Lista de tabelas}

Tabela 2.1 - Cronograma de Abertura do Mercado de STFC - 1999/2004 34

Tabela 2.2 - Leilão de Privatização das Empresas de STFC 34

Tabela 2.3 - Alguns critérios para identificação das estratégias encontradas na $\begin{array}{ll}\text { literatura } & 80\end{array}$

Tabela 2.4 - Critérios de Mensuração do Desempenho 85

Tabela 3.1 - Variáveis Estratégicas Selecionadas para a Pesquisa 95

Tabela 3.2 - Relação entre Estratégias Competitivas e Estratégias Genéricas 97

Tabela 4.1 - Classificação das Estratégias Competitivas para um Perfil Ideal de Diferenciação 112

Tabela 4.2 - Ênfase Relativa em cada uma das Estratégias Competitivas Antes e $\begin{array}{ll}\text { Após a Privatização } & 113\end{array}$

Tabela 4.3 - Caracterização das Forças do Ambiente Competitivo Antes e Após a $\begin{array}{ll}\text { Nova Regulamentação } & 114\end{array}$

Tabela 4.4 - Indicadores de Desempenho da Empresa Selecionada Antes e Após a Privatização 